\title{
'Keeping up appearances' - negotiating identities of being fit in older age: a multi-site ethnographic study of daily life in contemporary day centres
}

\author{
Christine $\varnothing \mathrm{ye}^{1 \star}$ (D), Reidun Norvoll ${ }^{2}$ (D) and Mia Vabø $\varnothing^{3}$ \\ ${ }^{1}$ Faculty of Health and Social Sciences, Centre of Care Research and Institute of Health and Care Research, \\ Western Norway University of Applied Sciences, Stord, Norway, ${ }^{2}$ Work Research Institute, AFI, OsloMet \\ University, Oslo, Norway and ${ }^{3}$ Norwegian Social Research, NOVA OsloMet University, Oslo, Norway \\ *Corresponding author. Email: Christine.oye@hvl.no
}

(Accepted 4 October 2021)

\begin{abstract}
As governments adapt to 'active ageing' policies, care services are increasingly oriented towards helping older adults to stay active in order to maintain their physiological and cognitive capacity. Day centres for the frail old adults are adding more planned activities to their conventional social programmes. Although evidence indicates that they may benefit from physical fitness sessions and brain training, little is known about the way in which the activation agenda influences social interaction among participants. The article aims to fill this knowledge gap by exploring how staff and participants manoeuvre between the new activation agenda and processes of coming to terms with the functional decline of ageing bodies. We draw on ethnographic data, collected in four day centres in Denmark and Norway, constituting participant observation of 18 days, 19 interviews with older participants and 18 interviews with staff members. With reference to the dramaturgical approach of Erving Goffman, we demonstrate how different fitness identities are negotiated on different social stages. Firstly, we identify a social stage at a crossroad between staff acting as motivators in training sessions and older participants as active contributors. We demonstrate how day-care staff assist participants in keeping up appearances as fit for one's age by recognising their performance and concealing flawed performances. Secondly, we identify a social stage where participants socialise with co-participants around the lunch table and other social events. Here the act of 'keeping up appearances' turns into a complex art whereby people strive to retain their fitness identity by comparing themselves with peers. Finally, based on observation 'backstage', we reveal how participants distance themselves from the functional decline of old age by claiming that they are fit enough. We conclude that day centres are contested sites for active-ageing policies.
\end{abstract}

Keywords: active ageing; day centre; fitness; identity; participation; ethnography

(c) The Author(s), 2021. Published by Cambridge University Press. This is an Open Access article, distributed under the terms of the Creative Commons Attribution licence (http://creativecommons.org/licenses/by/4.0/), which permits unrestricted re-use, distribution and reproduction, provided the original article is properly cited. 


\section{Introduction}

In response to an ageing population, governments around the world are embracing a policy strategy of 'active ageing' (World Health Organization, 2016). Apart from aiming for maximum participation, wellbeing, and improved health and functioning, active ageing is seen as part of a cost-efficiency strategy for keeping frail participants at home as long as possible instead of in costly institutional care (van Haeften-van Dijk et al., 2015). Increasingly, various forms of outpatient care, including day centres located in the community, are being established to support independent living (Carlsson et al., 2020) and ensure that older adults can continue to live in their own home (Orellana et al., 2020).

The policy of ageing in place has been a core aim of Nordic elder-care policy for more than 50 years. During the 1960s and 1970s, the infrastructure of tax-funded services for home-dwelling individuals expanded greatly. This was warmly welcomed by older adults themselves and community care commenced (Vabø and Szebehely, 2012; Tretteteig et al., 2017). In recent decades, however, as the service coverage of long-term institutional care has declined (Szebehely and Meagher, 2018), community care services have increasingly targeted home-dwelling individuals with severe physical and cognitive health challenges. These services are nevertheless profiled as interventions intended to enhance the capacity of older people to live independently at home. As elsewhere, day centres increasingly target older adults in need of rehabilitation and behavioural activation (Burch and Borland, 2001; Svidén et al., 2004; Doh et al., 2020) for the purpose of keeping them healthy and physically fit, and preserving their level of functioning (Hickerson et al., 2008; Iecovic and Biderman, 2013), including brain training for the optimisation of cognitive health (Libert et al., 2020).

The implicit message of contemporary active-ageing policies is that even frail older adults who are in their 'fourth age' will benefit from being more active. However, there is no precise, universally agreed definition for the concepts of being active and active ageing. According to Boudiny and Mortelmans (2011), the term 'active' tends to be narrowly understood in terms of traditional 'youthful' activities, which remain unattainable for many of the frail older adults in their fourth age. They argue that older people who are suffering from severe illness and disability may stop trying if they feel that their pursuit of valued activities is impeded by circumstances beyond their control. They further claim that policy makers should be aware of the danger of causing psychological distress among people who do not manage to continue activities they previously valued. Rather than pushing people to resist functional decline, they should instead consider how older people in their fourth age can be encouraged to accept the inability to perform and to search for new ways of remaining engaged (Boudiny, 2013) or new ways of living for the present and taking it one day at a time (Clarke and Warren, 2007). In the same vein, Gilleard and Higgs (2017) and Libert et al. (2020) point to the danger that promoting a fit mind and body in older age might possibly lead to social stratification and division among older populations. Fear of decline and dependency may lead to the 'othering' of those who are less active. The authors argue that social pressure on older people to act responsibly as managers of their own health not only plays out as social pressure to keep the body fit, it also relates to the will to resist age-related cognitive decline. 
Against the backdrop of these critical perspectives, this article seeks to explore the lived experience of active-ageing policies targeted at day-care participants in their fourth age. This article draws on ethnographic data collected in day centres in Denmark and Norway in an effort to increase our knowledge about how staff and participants manoeuvre between the new activation agenda and processes of coming to terms with the functional decline of ageing bodies. The article examines how notions of fitness are played out as identity performance and negotiation within day centres. With reference to the dramaturgical approach of Erving Goffman, we demonstrate how processes of identity negotiation take place on different social stages, involving different actors and audiences who interpret fitness in slightly different ways.

\section{Day-care institutions}

'Day centre' is a generic term describing building-based services that offer a wide variety of programmes and services (Orellana et al., 2020). Although day centres are regarded as important elements in contemporary care policies, they are largely neglected in statistical reports and research (Sundström et al., 2011; Hagan and Manktelow, in press). This is underpinned by the fact that services offered in day centres are commonly regarded as supplementary services within a more comprehensive care landscape (Sundström et al., 2011; Carlsson et al., 2020) and may take various forms depending on structural considerations such as funding and governance of local care systems (Orellana et al., 2020). Hence, the term 'day centre' covers a broad variety of social institutions. However, some day centres are anchored in a medical model that is preoccupied with physical functioning and rehabilitation (Iecovic and Biderman, 2013), while other day-care institutions are anchored in a social model that arranges for social and leisure activities (Miller, 2016). Some, for instance, are open to all citizens above a certain age (Carlsson et al., 2020), while others are adapted to the needs of specific groups, such as people suffering from dementia (Anderson et al., 2015; Strandenæs et al., 2017) or people in need of rehabilitative services (Tollén et al., 2007; Doh et al., 2020).

In Denmark and Norway, day-care services are typically targeting frail, homedwelling older adults in their fourth age who often have social needs (Lassen, 2014; Førland and Rostad, 2019). The services are needs-assessed based on the individual user's social, mental and physical enablement needs, but they can also be assessed on the basis of family care-givers' needs for respite services (Tretteteig et al., 2017). As they are integrated into the community health and social care system, day-care services will often be offered as part of a care package comprising several elements, such as home nursing, domiciliary care and meals on wheels. Day-care services are publicly funded but will often charge small user fees. They are typically run by the municipality or a non-governmental organisation on contract, or are co-located and driven in collaboration with member-driven senior centres for citizens in their third age. Typically, they will be staffed by trained care staff such as practical nurses and assistant occupational therapists and occasionally by staff with a bachelor's degree in an area such as nursing, occupational therapy, etc. Most day centres have a social profile, but they are increasingly emphasising cognitive and physical reablement (Lund and Engelsrud, 2008; Førland and 
Rostad, 2019). Hence, local governments in Norway and Denmark are often renaming their day centres as 'activity centres' (Liveng, 2014).

To the extent that researchers have taken an interest in day-care institutions, the largest body of evidence concerns the social and preventive outcomes of various interventions (Orellana et al., 2020). Studies indicate that different forms of activities targeting frail participants have benefits for both physical and cognitive health (e.g. García-Martín et al., 2004; Tollén et al., 2007; Seddigh et al., 2020). For instance, Kuzuya et al. (2006) found that participating in activities such as physical exercise improved activity of daily living functions among participants at an activity centre. Rizzuto et al. ( 2012) found that physical activities in day centres can even enhance life expectancy. García-Martín et al. (2004) and Seddigh et al. (2020) both concluded that social activities and support in day centres reduced the level of depression and loneliness and increased the level of life satisfaction among the older adults.

While the majority of studies have focused on the impact of being more active, only a few qualitative studies have explored how these institutions are perceived from the 'inside' by those who attend or work in such places (Orellana et al., 2020). One exception is Carlsson et al. (2020), who explored the 'doing of care' in culturally specific day centres. The authors observed how care staff mediated between the lifeworld of older people and the wider care landscape governed by norms, guidelines and policies. For instance, they demonstrated how familiar activities such as knitting and watching television facilitated interaction among participants, whereas various forms of physical and cognitive exercise would sometimes be perceived as infantilising and meaningless. Faced with these kinds of tensions, care staff constantly translated and negotiated their own practices. Despite staff formally including participants in decisions concerning activities, older people may act subversively, for instance by placing themselves in front of the television instead of participating in crafts or bingo (Carlsson et al., 2020), or by simply not paying attention during staff-facilitated activities, falling asleep or more actively opposing the activities that have been arranged (Salari and Rich, 2001). Miner and Rich (2001) observed that participants who became bored by staff-facilitated activities or who preferred interactions with co-participants simply disregarded these activities. Shulamith (1999) noted that, insofar as participants spontaneously became more active on their own, they were able to express themselves in a meaningful and empowering manner. However, tensions that arise in day centres do not relate solely to staff encouraging attendees to join activities; tensions may also be induced by participants othering the behaviour of their frailest peers (Libert et al., 2020). In a study of a Norwegian senior centre, Lund and Engelsrud (2008) found that participants who subscribed to the active-ageing discourse distanced themselves from the frailest participants, thereby denying the negative value of the normal ageing process.

\section{Design and methods}

The data used in this study were collected within a more comprehensive multiple case study called Creating Integrated Person-centred Care in Different Settings (CONTEXT) that explored changing community care landscapes in Denmark 
and Norway. The study was conducted in 2018/2019 and was organised as a collaborative team ethnographic study consisting of ten researchers with multidisciplinary backgrounds from both countries.

The project was based on a layered case study (Patton, 2002) with a research design that opened up several layers and focal points for possible analysis. Day centres were one of several services explored. We utilised a range of data sources from different levels in four different Norwegian and Danish municipalities, including: (a) policy documents, (b) semi-structured interviews with leaders and key professionals, and (c) field notes and on-the-spot interviews from rapid ethnographical studies in different parts of the care system (Armstrong and Lowndes, 2018). Each site visit included a field work debrief focusing on emerging and overlapping themes. Issues raised were followed up with new observations and reflection notes. This gave us comprehensive data material that was used for analysis within and across cases (Patton, 2002: 448). More detailed research questions were developed by dedicated researchers in collaboration with the research team.

For the purposes of this article, we draw mainly on data collected by the first author, who made participant observations in day centres at all four research sites. Observation was performed by the first author, who was often situated on the edge of activities as a participant observer, taking field notes on observable interaction sequences among older participants, between participants and staff, and between staff. In order not to disrupt the flow of the moment, the field notes were made immediately after the interactions or informal interviews took place. The second and third authors explored day centres more indirectly through policy documents and interviews with administrators, leaders and professional care staff involved in assessing needs for day-care services. By focusing on the everyday life situation of severely dependent home-care clients, the second author gained insight into the role that day-care services played for individual participants.

Although the four day centres differed to some extent with regard to organisation and activity menus, they shared many similarities. They accommodated participants who had been through a formal needs assessment by local authorities. It was typically assessed that participants should attend the centre between two and three days a week, four days at the most and one day at the least. All day centres were in nearby town centres, open every weekday, but differing somewhat in terms of how many hours they were open, ranging from three to seven hours per day. The day centre services were needs-assessed, but differed slightly according to social, mental or physical enablement needs. One of the day centres was reserved for persons with cognitive decline only, while another day centre stated that its services were reserved primarily for older persons with cognitive or physical rehabilitation needs. Moreover, in all four day centres the participants were assessed on the basis of family care-givers' needs for respite services, although this was not a formal assessment criterion in the Danish services.

All of the day centres prioritised planned activities, including both physical and cognitive exercises of different kinds. Moreover, staff and participants interacted in similar ways. For instance, at all sites the care staff made efforts to motivate participants to take part in planned activities, and at all sites the participants were free to manoeuvre between staff-facilitated activities and more traditional social and recreational gatherings such as meals and conversation tables. 
The field work in the day centres lasted between five and nine hours each day for five weekdays in each municipality. The first author observed staff and participants during different types of daily life activities such as preparing and eating meals (preparing and serving breakfast, lunch, dinner or other small meals such as cake or fruit) as well as during planned activities facilitated by staff or spontaneous activities initiated by the participants themselves. Activities were often indoor physical activities such as individual or group physical exercises, dance sessions or physical games, as well as outdoor activities such as group walks and excursions to church, museums, gardens, grocery stores, etc. All of the day centres offered various forms of brain training such as bingo, crossword puzzles, other types of puzzles, different types of board games, and cultural activities such as reading groups (newspapers), writing groups with authors, film-watching, singing sessions, carving, knitting and needlework, or other handicraft activities.

The study includes participant observations (for a total of 18 days), including typical ethnographic walking-and-talking conversations with both staff and older participants. In addition, 19 participants (six men and 13 women) were formally interviewed by Dictaphone about their experiences with day centres. The youngest interviewee was in her mid-seventies and the oldest in her mid-nineties. In addition, conversational interviews were conducted informally during meals, during conversations over coffee and during walks or excursions; the youngest of these interviewees was in his mid-sixties and the oldest in her late nineties. Six of the formal interviews were in groups of either two or three participants, and three interviews were with one participant at a time. Approximately half of those interviewed had some form of cognitive decline but were considered by staff as being sufficiently competent to give informed consent. Moreover, five home-care attendees of a day centre were interviewed in their own homes. A total of 18 staff members, all holding a permanent position in a day centre, were also interviewed, either individually or in pairs. The interviews lasted between 20 and 65 minutes. The staff interviewees consisted mainly of practical nurses, but there were also staff with an activator, nursing, occupational therapy, physiotherapy or sport educator background.

\section{Analyses}

NVivo (QSR International, Melbourne) was used to analyse verbatim transcriptions of the formal interviews. We used initial coding procedures based on 12 thematic codes for the whole of the ethnographic material, as well as more fine-grained codes, developed by the first author, when analysing the interviews and field notes from day centres. The second author analysed the interviews with the care recipients. For the purposes of this particular article, we paid particular attention to the field notes and interviews that were analysed using setting-specific coding (Lofland et al., 2006), which broke down the ethnographic material as follows: (a) physical activities, e.g. physical exercise, walks outdoors, dance sessions, (b) cognitive activities, e.g. board games, bingo, (c) cultural activities, e.g. singing sessions, writing groups, handicraft groups, and (d) social activities, e.g. meals, coffee breaks, shopping.

For the purposes of this article, we found that several Erving Goffman dramaturgical concepts were useful as sensitising concepts. Goffman's concepts helped 
us see how attendees of the day centres present themselves to others, both front stage and backstage, i.e. in social situations where the performance of being fit was more or less directed by care staff. In describing the role of care staff, we allude to Goffman's (1959: 212) concept of 'tact', which is how staff help older participants to avoid or recover from a flawed performance, and which refers to concepts of deference and demeanour as a form of ceremonial care (Goffman, 1956). Moreover, the dramaturgical approach helped us look at how older participants stage their performances for others as a way of managing their identities, e.g. to defend themselves from the unwanted scrutiny of others (Goffman, 1959). The concept and understanding of identity negotiation as derived from the work of Swann (1987) also builds on social interactionism. Social identity is an expression of one's personal life stories, preferences and goals, and is in constant negotiation based on responses and feedback from the individual's co-participants. The interaction proceeds smoothly if there is consensus on how to claim identity, as long as the identity negotiation is self-confirmatory. In contrast, the interaction collapses when one of the parties does not agree or when some other form of resistance occurs (Goffman, 1959; Swann, 1987). In our analysis, we demonstrate how different fitness identities can be both honoured and challenged, depending on which of the three social stages the actors are operating.

We have organised the presentation of our findings into three sections, based on an analytical distinction between three different social arenas, metaphorically labelled according to Goffman's dramaturgical concepts. First is the main or front stage of planned activities, where care staff acted as directors taking a leading role in saying what it means to be fit and assisted in the self-presentation of being fit. Second is an improvisational stage, where the participants socialised with peers during meals or social activities and kept up the appearance of being fit in the eyes of their peers. Finally, there is the backstage, where the participants enjoyed being socially connected rather than playing the fitness game - in other words, where they 'kept fitness games at a distance'.

\section{Research ethics}

Ethical approval was obtained from the Norwegian Centre for Research Data (NSD). Informed consent forms were collected from all interviewees. The leaders of the day centres were informed of the guidelines for privacy protection and research ethics with regard to observing participants. Particular attention was paid to human dignity and privacy, given the nature of the target group (the frailest of the older adults). Anonymity was secured by slightly redrafting the cases and interviews where these were recognisable and by not indicating the location of the ethnographic observation.

\section{Assisted self-presentation of being fit}

At all four sites that we visited, the active-ageing policy framework had influenced the way that leaders and staff talked about the purpose of the day-care service. Staff interviewees often underscored the importance of stimulating the frailest 
participants, both physically and cognitively. Helping participants to stay physically fit was high on the agenda:

We focus on the older adults' balance and level of functioning for the participants to be physically fit in order to stay in their own homes as long as possible. (Leader)

However, they also emphasised the importance of cognitive training: 'This game with numbers is a way to train their cognitive capability' (staff member).

Staff interviewees also related stories of the success of their efforts to get the participants to be more active. A typical storyline is as follows:

We had a participant who was very inactive, sitting at home watching television all day long. Initially she came in a wheelchair and could hardly walk more than a hundred metres. Now she is very active; she can walk more than five kilometres. (Staff member)

Care staff obviously saw their professional role as that of a motivator or activator who encourages people to use their physical and cognitive capabilities. In interviews, staff would underscore the importance of not performing activities for the participants, but rather letting them find out how to do things by themselves: 'I hide my hands and I let them perform the activities, either incorrectly or correctly' (staff member). Moreover, in interviews the staff were aware that they should not pinpoint what the participants do not master but, rather, praise what they are able to do and pretend that they cannot master the activity either: 'I make myself more stupid than I am by pretending that I cannot cope either, especially when they cannot master an activity' (staff member). By not pinpointing what the participants cannot master, the staff do not challenge their identity by implying that they are less fit than they used to be. Rather, they do the opposite: staff provide cover by pretending that they themselves are sometimes incapable: 'I ask for a word that I pretend I can't remember for them to try and find the right word, even though it takes time' (staff member).

From an observer's perspective, the motivating role of staff was particularly evident during different kinds of physical activities, such as physical exercise indoors, long walks combined with exercise in the park or walks in the neighbourhood. As a minimum, staff in one day centre would encourage all participants to join its daily 20-minute physical exercise session-despite the participants' differing levels of physical function. In these sessions, a facilitator would act as a director on stage, taking a leading role in talking about how to behave as a fit participant. The facilitators made great efforts to create a playful, happy atmosphere in an exercise session where participants were organised in pairs:

During the exercise session, the facilitator used humour to make the participants more active or to get them to try harder to manage the exercises. At first, she was approaching the male participants and saying, 'Who is the coachman and who is the horse?' and then, later, saying, 'Let me see who the strongest man is in this room.' The participants were laughing and following the clock on the wall. 'You lie', they said, pointing at the staff member facilitating the exercises. 'You promised 
it would only last three minutes, and it has lasted at least twice that long.' Afterwards, a staff member gave one of the male participants some weights, and when she turned around, he picked up a pair of lighter weights than agreed, so at the end of the exercise session the staff member said: 'Tom, you are cheating. Do you think I did not notice?' They all laughed. (Observation)

This brief episode exemplifies how identities as fit were negotiated by staff in the role of motivator in a playful way, opening the way for the participants to join the play by letting them play the role of 'naughty school-boy'. In another case, we observed how staff used humour to negotiate the identity of being fit and lured a passive participant into taking part in the exercise session. The following excerpt illustrates this role:

Staff prepared for the collective physical exercise session by finding chairs to place in a row, and thereafter used a microphone to announce the exercise session. Most of the participants found a chair to lean on while doing the exercises. The staff facilitator tried to motivate a male participant who gave no sign of participating: 'Hans, please help me out here, I need a fit guy like you to assist with the exercises.' Hans gets on to his feet and replies: 'Since you are the one who is asking, I will for sure help you out.' He hurries over to the facilitator and takes a place beside her, doing the exercises in an enthusiastic way without leaning on a chair. (Observation)

This may be seen as an act of 'assisted self-presentation' (Næss et al., 2016), whereby staff generate an opportunity for frail older participants to experience a joyful social moment. We recognised several incidents of assisted self-presentation during staff-facilitated activities. For instance, we noticed different ways in which staff downplayed flawed performance. They would almost unnoticeably contribute to making the frail older participants appear fit through acts of deference (Goffman, 1956):

A lady cannot find her mobile phone. A co-participant looks at her and says: 'We have not seen your phone', while whispering to the others that she always forgets stuff. A staff member responds by saying: 'She was very clever today and left her phone at home, because she found out that she would not need her phone on such a busy day.' The lady smiles and says: 'That's right, I don't need my phone here.' (Observation)

Insofar as staff were facilitating activities or attending conversations during meals, they played an active role in keeping the atmosphere pleasant and ensuring that individual participants did not 'lose face' (Goffman, 1956). However, as will be elaborated in the following two sections, identity negotiation also played out more spontaneously without the staff acting as moderators.

\section{The complex art of 'keeping up the appearance' of being fit among peers}

Although contemporary day centres are often portrayed as sites for planned activities and becoming more active, they continue to be perceived as social gathering places for older adults. In interviews they regularly talked about their time in a 
day centre as a break from their monotonous and boring routine life at home. It was obviously a highly valued arena for social interaction - for some, being there was the high point of the week. While shadowing home-care staff during their morning visits, we observed several older women who were dressed up in silk blouses and jewellery, eager to socialise with peers. When we were observing social gatherings around the lunch table or small talk at coffee tables between events, or observing other participants taking part in activities, we noticed various subtle ways in which they were claiming an identity as fit. Identity negotiation in these situations was played out as on a stage for improvisation. The participants had no director but played out their social roles and identities as being fit, sometimes fluently as in days gone by, other times in a more stumbling fashion.

Quite a few of the participants demonstrated their fitness by showing what they could still manage to do despite their longevity and/or severe illness. By making small remarks such as 'I usually go for a walk with my family' (female participant) or 'I still have my driver's licence' (male participant), they were discreetly hinting that they were still going strong and were fit for their age. Presenting themselves for an outside researcher, they would underscore more explicitly how successful they were in actively ageing in the right way: 'Since I started to engage in the physical activities, I've seldom used this one' (pointing at her rollator) (female participant with a rollator), or 'I am also pretty good at doing my physical exercises at home' (male participant with a rollator). Some would also compare themselves with peers who were not managing as well. An older interviewee said: 'I can see that today I am the only one participating here who is not using a rollator' (male participant).

However, some were more inclined to express a personal identity of being physically fit by referring to their previous healthy habits and regretting that sudden illness prevented them from retaining their highly active lifestyle: 'I used to go to a fitness centre but look at me now. I need help to do everything: cook, clean the house ... my husband does everything' (female participant with a rollator). Statements like this exemplify how participants sometimes spoke from the position of their 'ageless self, stressing their continuity of identity despite their declining functional capabilities.

Whereas many of the participants were still fit enough to manage the art of socialising, conversations and arrangements were regularly disrupted by participants who were unable to conform to social norms. These situations often involved a process of 'othering' (Libert et al., 2020). Those who had a self-identity of being cognitively fit frequently distinguished themselves from those who showed signs of cognitive decline. Deviant behaviour due to confusion and dementia was used as a reference point for assigning people a social identity as old and frail and as not being among those regarded as fit for their age. Participants chatting around a coffee table would, for instance, comment on individuals by name: 'When I was here a couple of weeks ago, Paul came to this group. Now I can see that he has been placed in the senile group' (male participant). In formal interviews, interviewees would speak from an outside position when informing the researcher about the clientele of the day centre: 'Many of the participants here are pretty confused' (female participant in a wheelchair) or 'On Thursdays the participant group is a bit heavy quite a few will need help one on one, some are not right' - pointing at her head - 
'they have problems talking, so it is not so easy then' (female participant with a rollator).

Two older interviewees, close friends, spoke with disgust of the deviant behaviour of one of the participants:

We have someone here, we have a lady who will pick her nose while we eat. We do not like to see that, do we?' - asking her friend to comment - 'Yes, and she eats a lot also. (Female participants diagnosed with dementia)

During meals and social activities, several of the participants would roll their eyes or make comments on the flawed performances of co-participants who showed signs of memory loss or confusion. This episode illustrates how arranged activities functioned as a social scene for the participants to compare their own brain fitness with that of other participants:

Bingo was arranged just after lunch based on the wishes of the participants. The staff facilitated the game and the participants placed themselves strategically around the living room. The best seats are in front of the gift table, and friends try to find seats next to each other. The staff also helped participants when they needed help to either hear or see the numbers. Co-participants might comment on another older person's function when participating in bingo by whispering to a friend: 'Can you see that Mrs Hansen is not managing her board of numbers? I wonder if she is getting senile.' When the bingo session is over and gifts are being handed out, they try to find their seats in the sitting groups where they belong. When one of the participants could not find her place, a co-participant swiftly guided her to the right place and said, 'Your place is not in this group, you belong to the other group over there', pointing to the door where the cognitively impaired are grouped together. (Observation)

When observing the non-directed social interaction of the day-care participants, it was striking to note how their negotiations over their fitness identities changed in character. In the staff-directed activities, however, social identity as fit related to demonstrating the will and capacity to perform. The example below, taken from field notes, exemplifies how efforts to appear fit by demonstrating physical fitness can fail. An older woman who was slim and physically fit was set straight by co-participants who made her aware of her memory loss and confusion:

After the physical exercise session, a meal of meatballs, potatoes and sauce was served. The participants looked for their seat and name tags. An old woman was looking for her purse. Leading her carefully towards her seat, staff assured her that she had left her purse safe at home because she did not need the purse that day. When seated, she helped herself to the food that was being served and passed on the sauce. A female participant sitting next to her said: 'Take some sauce. You complain all the time that you're so skinny your trousers fall off.' She replied: 'It's better to be skinny than fat. I always run, my husband and I, we are running all the time, but now I can't find the belt to my trousers.' She left the table and looked around the centre for her belt. One of the other 
participants who was sitting at the table pointed at her own head and commented:

'She is nuts.' (Observation)

The example cited above demonstrates how the participants operate with a multidimensional concept of fitness and how this again makes claiming an identity as fit a complex art. One cannot successfully present oneself as slim, sporty and quick of tongue if one does not also have a fit mind. Hence, being on the improvisation stage at the day centre is risky for the participants, partly because they have no director telling them what to do and partly because they have a far more critical audience.

\section{Keeping fitness games at a distance}

In addition to planned activities, meals and other gatherings, the day centres provided small periods of time for more relaxed backstage life. Whereas frontstage behaviour reflects internalised norms and expectations for behaviour shaped by that setting, backstage behaviour permits the actors to behave in ways that reflect their 'true' selves (Goffman, 1959). As in the backstage area of a theatre, these time periods often occurred between activities. It was occasionally possible to observe some of the attendees skulking off - sometimes to sit down and talk privately, or else to just take time out or smoke a cigarette with a friend. This typically occurred in the minutes before the exercise sessions started. Some of the 'shirkers' would then freely explain (to the researcher) that they did not bother, simply because they felt that it was too much for their bodies: 'My back hurts, my legs and knees do not function, so the exercises are too hard for me to follow, but I would have liked to participate if I could (female participant with a rollator)', or 'I do not like the physical exercises at the activity centre - my body hurts' (female participant).

Some of the participants would politely withdraw, stressing that the level of activity was too high and saying, for instance, 'It is okay to do exercises, but I am not good at doing them. I prefer to go for a short walk' (female participant diagnosed with dementia) and pointing to the small trail outside the day centre. Others attributed their resistance to the nature of the arrangement. One individual disregards the sessions because they have not been adapted for their health issues: 'I would have liked to participate in the exercises, but exercises of this kind do not help me with my balance problems' (female participant with a rollator). A few others said that they did not participate simply because they did not like being part of a silly party game: 'You are asking me if I participate in physical exercises here? Oh no! I have other things to do' (male participant).

As mentioned earlier, participants who refused to join activities were sometimes gently pushed to participate. In one situation, one of the employees was wandering around enthusiastically encouraging some reluctant participants to join a walking group: 'You know that your health will benefit from joining us on a walk in the park' (staff member). When the staff member encouraged one participant to go for a walk, she replied, 'I have celebrated too many birthdays and my back is therefore not fit for a walk in the park' (female participant with a rollator), and she laughed. Likewise, two other ladies tried to get around participating in planned activities because they obviously had a great time chatting: 
A staff member approached two ladies who were still sitting at the breakfast table. 'Ladies, why don't you follow me into the living room for some fun exercise?' The ladies looked at each other and said, 'We would rather go for a walk outside.' Looking out the window, the staff member said: 'It's raining.' The ladies replied: 'We are sure the sun will be shining soon.' The two ladies found their coats and went to the door. However, they soon returned (it was still raining), found chairs in the living room and began chatting with each other again, but they did not participate in the exercise. (Observation)

Some participants obviously felt that the exercise sessions were boring or that they were infantile games - not what they regarded as 'normal' activities. One episode from the field notes describes what was said among some of the participants who had dropped the exercise session:

Three participants did not show any sign of wanting to participate in the physical exercise. A staff member tried to motivate them to participate by saying: 'Come on, exercise is starting up soon!' After the staff member left, one of the ladies said: 'This is not proper physical exercise. I used to be active in athletics, so I know that this is not how it should be.' Another participant commented: 'I do not want to participate either', and followed up by mocking the exercise session by moving his leg slightly in a circle - just as they were instructed to do. The other drop-out participants laughed, and one of the ladies said: 'No, this is not proper physical exercise when you just move one foot a little bit and then the other foot or arm. What is that, eh?' (Observation)

Rather than taking part in the social play around the scheduled activities, these three participants created social bonds by chatting and mocking the arranged activities. In this way they shared a social identity as fit enough for their age - fit enough to create a critical distance between themselves and staff-facilitated arrangements.

\section{Discussion}

Active ageing aims to extend the expectancy of a healthy life and improve the quality of life for all people as they age, including those who are frail older adults, disabled or in need of care (World Health Organization, 2016). Regarding the latter group, social gerontologists have warned about being too idealistic: an overly youthful conception of 'being active' (Boudiny and Mortelmans, 2011) and an overly optimistic belief in training as an extension of fitness and health management may bring about a new source of social exclusion among older people (Libert et al., 2020). Physical exercise and other training technologies may simply be too hard to adhere to for people who have accepted that the future is downhill. In respect of the growing belief in increased activity levels as a measure for easing off the fiscal pressure on care provision (Boudiny, 2013; van Haeften-van Dijk et al., 2015), there is also a danger that policy makers may give less priority to those things that matter to people who are approaching the end of life.

By exploring how notions of 'being fit' are talked about, performed and negotiated by participants and staff at contemporary day centres in Denmark and Norway, we have demonstrated that there are several competing notions of fitness. 
In adhering to the idea of preventing and delaying decline and dependence, staff interviewees have encouraged participants to see the benefits of taking care of their body and mind through various forms of training. Day-care participants themselves are more inclined to talk about fitness as something less controllable, whether as a stable self-conception developed over a long lifespan or as a matter of luck. They may, for instance, present themselves as the fit one who does not need to use a rollator (like everybody else does), or as the unlucky one who was always fit and had a healthy lifestyle but is now disabled due to chronic illness. Observing the social life at day centres through the lens of identity negotiation, we find that both staff and participants contribute to more intermediate conceptions of fitness. We find that the performance of fitness is complex and shifting, depending on which social stage the social interaction is being played out.

Firstly, we observed that, in their role as activity facilitators on the front stage, staff used a lot of humour to lower the threshold for participation and to reduce performance anxiety. Although they frequently reminded participants of the importance of being fit, they would do so in a jocular manner. They actively reshaped social situations (Fjær and Vabø, 2013) into a fitness game whereby they pretended to be the drillmaster for unruly children, inviting the participants to join in the game not as 'true' athletes but as joyful people with a sense of humour. During the exercise session they would continue to support the participants' self-presentation by recognising their performance and concealing any flawed performance. For instance, they would almost imperceptibly assist a 'fit way of performance' through acts of deference to hide poor demeanour (Goffman, 1956). As such, 'keeping up the appearance' of being fit was the 'product of joint ceremonial labour' (Goffman, 1956: 493) or an act of 'assisted selfpresentation' (Næss et al., 2016). However, by doing so, staff carry out active-ageing policies by constantly motivating and slightly pushing participants to exercise and, accordingly, optimise their performance of fitness.

Secondly, in more conventional social gatherings staff played a slightly less significant role, leaving the stage to the older participants themselves in more of a non-directive and improvisational way. For instance, signs of cognitive decline and confusion would frequently be remarked upon, both behind the back of the 'victim' or in narratives related to the researcher. In other words, participants were more concerned with the cognitive health of their co-participants than with their physical health. We perceived these comments as a kind of othering - a way of marking off a distance between themselves and peers who might be suffering from dementia (Lund and Engelsrud, 2008; Libert et al., 2020). On the one hand, we saw this demarcation strategy as a way for older adults to claim an identity as cognitively fit. On the other hand, it implicitly communicated that people who strive to pull themselves together in the eyes of others are at risk of being ostracised and identified as 'not so fit any more'. Accordingly, mental infirmity seems to continue to be regarded with stigma and is not compensated for by other forms of fitness. On this improvisation stage, having a strong and youthful body is not enough to be included in the company of the 'fit older person'. Rather, in these settings, 'keeping up the appearance' of being fit for one's age requires the more sophisticated art of behaving properly. 
Finally, we observed participants expressing a need for time-out from the official day-care programme by operating backstage, sometimes as a way to sneak away from an exhausting activity session, at other times simply because they wanted to hold on to a moment of pleasure talking to a friend. This kind of subversive behaviour can also be found in other, similar studies of day-care institutions (Salari and Rich, 2001; Carlsson et al., 2020). We interpreted the need they expressed for time-out as part of the mental attitude of taking one day at a time (Clarke and Warren, 2007) and seizing the day if something enjoyable occurs. Participants socialising 'privately' - ignoring the official programme because they have managed to create a relaxed and enthusiastic atmosphere-occasionally may tend to laugh and make ironic comments about the 'fitness games'. This way of 'ganging up' on planned activities suggests that these participants mutually confirm and affirm one another's self-conception as 'fit enough' - fit enough to have a good time without clowning around.

Day-care settings are contested terrain where active-ageing policies accentuate the virtue of doing activities for the purpose of keeping fit and maintaining physical functioning (Iecovic and Biderman, 2013; Lassen, 2014), whereas the target group of the frail older adults attend these places mainly because they regard them as an opportunity for being (as they are) with peers. However, neither staff nor day-care participants are just passive recipients of top-down policies; they are themselves agents who actively shape the enactment of policies through various forms of identity negotiation (Swann, 1987). By exploring the processes of identity negotiation, our analysis suggests that it is pointless to mobilise people in their fourth age to identify fully with the idea of doing various forms of exercise to keep the body and brain in good shape. These people participate in various forms of exercise not necessarily for the sake of fitness but to satisfy their social needs. Hence, rather than focusing on the instrumental aim of a fit body, day-care staff should concentrate on shaping exercise sessions into playful and inclusive games where being together and having a laugh is just as important as moving the body.

Our analysis calls for more attention to be paid to conventional social activities in day centres. By focusing on day-care participants' inclination to display identity cues related to cognitive fitness, we have demonstrated how this may have a negative impact on people who struggle to follow the common practice of socialising. Again, we believe it is important to be aware of the value of assisting the frailest and most vulnerable among the old in their self-presentation. However, as Næss et al. (2016: 158) emphasise in their conceptual discussion, assisted selfpresentation is a balancing act whereby care staff are attentive to the incapacity of the older person without disregarding the fact that the same person may be in need of autonomy in certain situations. There is always a danger that care staff might misstep, either by failing to recognise the vulnerability of participants or by failing to respect their agency and autonomy. In respect of the latter, our analysis demonstrates how day-care participants who take time out to socialise privately with one or more friends flourish during these unguarded moments. The counternarratives from participants who find staff-facilitated activities ineffectual or 
infantilising should be taken seriously and not simply ignored. With reference to the promising practice of shaping social situations (Fjær and Vabø, 2013) in nursing homes, we believe that care staff should move beyond their role as activators and focus more on generating opportunities for spontaneous interaction.

\section{Limitations}

It is beyond the scope of this paper to discuss how practices in day centres may be shaped by different structural and cultural preconditions. Doing research across different national and local settings, we have identified and discussed contextual differences across sites which potentially might have added greater nuance to the topic, including different staffing levels, different ways of organising activities, different skill mixes and differences in clientele due to rural and urban community settings, etc.

By relying on rapid site-switching and thus spending only one week in each day centre, the opportunities to establish trusting relationships with day-care participants were limited. Accordingly, we may have missed some important aspects of their self-conceptions.

\section{Conclusion}

In exploring how staff and participants negotiate fitness identities in day centres, we find that there are several stages available on which participants can perform as being fit for their age. Fitness is demonstrated on the main stage during planned activities in the eyes of peers and staff. Here, being fit is perceived as equivalent to being willing to participate and to contribute to a joyful happening. In contrast, on the improvisational stage, among peers, performing fitness is more about presenting oneself as cognitively fit and able to socialise according to social norms for good behaviour. On this social stage, 'keeping up appearances' is a complicated art of identity negotiation whereby participants strive to hold on to their identity by presenting themselves for, and comparing themselves with, their peers. The most cognitively fit will sometimes accentuate their own fitness by mocking or ridiculing the misconduct of the most cognitively frail older adults.

Day-care staff made great efforts to 'cover up' flawed performances of participants operating on these social stages. They did their best to implement and optimise active-ageing policies by reassuring participants and assisting them in taking part in their programmes for being more active. In contrast, when operating backstage, participants enjoyed living for the moment and holding on to moments of joy. Some made ironic comments about the monomania of old-age fitness and claimed that they were 'fit enough'. Hence, day centres appear to be a contested site for active-ageing policies and at odds with identities of being non-productive and frail in the fourth age.

Financial support. The project Creating Integrated Person-centred Care in Different Settings (CONTEXT) was supported by the Norwegian Research Council (NFR).

Ethical approval. Ethical approval was obtained from the Norwegian Centre for Research Data (NSD, reference 128713). 


\section{References}

Anderson KA, Dabelko-Schoeny HI, Fields NL and Carter JR (2015) Beyond respite: the role of adult services in supporting dementia caregivers. Home Health Care Services Quarterly 34, 101-112.

Armstrong P and Lowndes R (2018) Creative Teamwork: Developing Rapid, Site-switching Ethnography. New York, NY: Oxford University Press.

Boudiny K (2013) 'Active ageing': from empty rhetoric to effective policy tool. Ageing \& Society 33, 1077-1098.

Boudiny K and Mortelmans D (2011) A critical perspective: towards a broader understanding of 'active ageing'. Electronic Journal of Applied Psychology 7, 8-14.

Burch S and Borland C (2001) Collaboration, facilities and communities in day care services for older people. Health and Social Care in the Community 9, 19-30.

Carlsson H, Pijpers R and Van Melik R (2020) Day-care centres for older migrants: Spaces to translate practices in the carelandscape. Social \& Cultural Geography 1470-1197. https://www.tandfonline.com/ doi/pdf/10.1080/14649365.2020.1723135.

Clarke A and Warren A (2007) Hopes, fear and expectations about the future: what do older people's stories tell us about active ageing? Ageing \& Society 27, 465-488.

Doh D, Smith R and Gevers P (2020) Reviewing the reablement approach to caring for older people. Ageing \& Society 40, 1371-1383.

Fjær EG and Vabø M (2013) Shaping social situations: a hidden aspect of care work in nursing homes. Journal of Aging Studies 27, 419-427.

Førland O and Rostad HM (2019) Variasjon og uønsket variasjon i kvalitet $i$ omsorgstjenestene [Quality Variation and Not Unwanted Quality Variation in Health and Social Care Services] (Report No. 4). Bergen, Norway: Centre of Care Research.

García-Martín MA, Gómez-Jacinto L and Martimportugués-Goyenechea C (2004) A structural model of the effects of organized leisure activities on the well-being of elder adults in Spain. Activities, Adaption \& Aging 28, 19-34.

Gilleard C and Higgs P (2017) Ageing, corporeality and social divisions in later life. Ageing \& Society 37, 1681-1702.

Goffman E (1956) Deference and demeanor. American Anthropologist 58, 473-502.

Goffman E (1959) Presentation of Self in Everyday Life. New York, NY: Doubleday Anchor Books.

Hagan RJ and Manktelow R (in press) 'I shall miss the company': participants' reflections on time-limited day centre programming. Ageing \& Society. Available online doi:10.1017/S0144686X20000689.

Hickerson B, Moore A, Oakleaf L, Edwards J, Swanson J and Henderson KA (2008) The role of a senior centre in promoting physical activity for older adults. Journal of Park and Recreation Administration 26, 22-39.

Iecovic E and Biderman A (2013) Quality of life among disabled older adults without cognitive impairment and its relation to attendance in day care centres. Ageing \& Society 33, 627-643.

Kuzuya M, Masuda Y, Hirakawa Y, Iwata M, Enoki H, Hasegawa J and Iguchi A (2006) Day care service use is associated with lower mortality in community-dwelling frail older people. Journal of the American Geriatrics Society 54, 1364-1371.

Lassen AL (2014) Billiards, rhythms, collectives: billiards at a Danish activity centre as a culturally specific form of active ageing. Ethnologica Europaea 44, 1, 57-74.

Libert S, Charlesworth G and Higgs P (2020) Cognitive decline and distinction: a new line of fracture in later life? Ageing \& Society 40, 2574-2592.

Liveng A (2014) Aktivitet - et forsvar mod dødelighed? [Activity - a defence against death]. Gerontologi 30, $8-14$.

Lofland JD, Snow D, Anderson L and Lofland LH (2006) Analyzing Social Settings - A Guide to Qualitative Observation and Analysis. Belmont, CA: Thomson Wadsworth.

Lund A and Engelsrud G (2008) 'I am not that old': inter-personal experiences of thriving and threats at a senior centre. Ageing \& Society 28, 675-692.

Miller E (2016) Beyond bingo: a phenomenological exploration of leisure in aged care. Journal of Leisure Research 48, 35-49.

Miner SS and Rich M (2001) Social and environmental infantilization of aged persons: observations in two adult day care centres. International Journal of Aging and Human Development 52, 115-134. 
Næss A, Fjør GE and Vabø M (2016) The assisted presentation of self in nursing home life. Social Science \& Medicine 150, 153-159.

Orellana K, Manthorpe J and Tinker A (2020) Day centres for older people: a systematically conducted scoping review of literature about their benefits, purposes and how they are perceived. Ageing \& Society 40, 73-104.

Patton MQ (2002) Qualitative Research and Evaluation Methods. London: Sage.

Rizzuto D, Orsini N, Qiu C, Wang H-X and Fratiglioni L (2012) Lifestyle, social factors, and survival after age 75: population based study. BMJ 345:e5568, 1-10.

Salari SM and Rich M (2001) Social and environmental infantilization of aged persons: observations in two adult day centres. International Journal of Aging and Human Development 52, 115-134.

Seddigh M, Hazrati M, Jokar M, Mansouri A, Bazrafshan M-R and Kavi E (2020) A comparative study of perceived social support and depression among members of senior day centres, residents in nursing homes, and elderly living at home. Iranian Journal of Nursing and Midwifery Research 25, 160-165.

Shulamith L-A (1999) From ritual to drama and back in a rehabilitation day-centre. Journal of Aging Studies 13, 315-332.

Strandenæs MG, Lund A and Rokstad AMM (2017) Experiences of attending day care services designed for people with dementia - a qualitative study with individual interviews. Aging and Mental Health 22, 764-772.

Sundström G, Herlofson K, Daatland SO, Hansen EB, Johansson L, Malmberg B, Dolores M, González P and Tortosa MA (2011) Diversification of old age care services for older people: trade-offs between coverage, diversification and targeting in European countries. Journal of Care Service Management 5, 35-43.

Svidén AA, Tham $\mathbf{K}$ and Borell L (2004) Elderly participants of social and rehabilitative day centres. Scandinavian Journal of Caring Science 18, 402-409.

Swann WB (1987) Identity negotiation: where two roads meet. Journal of Personality and Social Psychology 53, 1038-1051.

Szebehely M and Meagher G (2018) Nordic eldercare - weak universalism becoming weaker? Journal of European Social Policy 28, 294-308.

Tollén A, Fredriksson C and Kamwendo K (2007) Elderly persons' expectations of day-care rehabilitation. Scandinavian Journal of Occupational Therapy 14, 173-182.

Tretteteig S, Vatne S and Rokstad AM (2017) The influence of day centres designed for people with dementia on family caregivers - a qualitative study. BMC Geriatrics 17, 5.

Vabø M and Szebehely M (2012) A caring state for all older people? In Anttonen A, Häikiö L and Stefanson K (eds), Welfare State, Universalism and Diversity. Cheltenham, UK: Edward Elgar, pp. 121-144.

van Haeften-van Dijk AM, Meiland FJM, van Mierlo LD and Dröes RM (2015) Transforming nursing home-based day care for people with dementia into socially integrated community day care: process analysis of the transition of six day centres. International Journal of Nursing Studies 52, 1310-1322.

World Health Organization (2016) Ageing and Health. Geneva: World Health Organization. Available at https://www.who.int/ageing/GSAP-Summary-EN.pdf?ua=1.

Cite this article: Øye C, Norvoll R, Vabø M (2021). 'Keeping up appearances' - negotiating identities of being fit in older age: a multi-site ethnographic study of daily life in contemporary day centres. Ageing \& Society 1-18. https://doi.org/10.1017/S0144686X2100163X 